\title{
Overprediction and blocking in the McCollough aftereffect
}

\author{
MICHAEL E. SLOANE, JOHN W. P. OST, DEBORAH B. ETHERIEDGE, \\ and STEPHEN E. HENDERLITE \\ University of Alabama at Birmingham, Birmingham, Alabama
}

\begin{abstract}
The Rescorla-Wagner theory (Rescorla \& Wagner, 1972) of associative learning offers specific predictions about the associative strength of CS-US pairs when two or more CSs are conditioned to the same US separately and subsequently paired in a compound with the same US. The magnitude of orientation-contingent color aftereffects (AEs) was used as an index of associative strength in this study. The results of experiments using an "overprediction" (Rescorla, 1970) and a "blocking" (Kamin, 1969) paradigm conformed to the predictions of the Rescorla-Wagner theory. In Experiment 1, AEs were established simultaneously for horizontal-vertical and diagonal patterns. When observers subsequently viewed compound induction patterns, AE magnitude was found to be significantly decreased, relative to a condition in which observers did not view such an induction pattern. In Experiment 2, AE magnitude for a given test pattern following inspection of compound induction stimuli was significantly reduced by inspection of the other component prior to viewing the compound induction stimuli. The applicability of associative learning and feature-adaptation models of the McCollough effect is discussed.
\end{abstract}

In 1965, McCollough described an orientationcontingent color aftereffect (AE). A typical way to generate such an $\mathrm{AE}$ is to present an observer with magenta and black vertical stripes alternating every few seconds with black and green horizontal stripes. After inspecting these alternating chromatic gratings for several minutes, the observer, on viewing an achromatic test pattern composed of vertical and horizontal stripes, will see weakly saturated colors approximately complementary to those formerly paired with each orientation. The initial report of the McCollough effect (ME) gave rise to a large body of research, which has shown the original orientationcontingent color $\mathrm{AE}$ to be just one member of a large class of contingent AEs (see Anstis, 1975, and Stromeyer, 1978, for reviews).

While there is currently no comprehensive explanation for MEs, the literature is divided between neural adaptation and associative learning models (see Harris, 1980, and Skowbo, 1984, for detailed discussion of these alternatives). There has been an ongoing debate about the adequacy of each model to explain the wealth of empirical data on the ME (Allan \& Siegel, 1986; McCarter \& Silver, 1977; Murch, 1976; Skowbo, 1984, 1986). The neural model attributes MEs to the adaptation of units in the visual system that are assumed to be tuned for both color and orientation. The details of these neural models have

We regret to report that John W. P. Ost passed away on April 13, 1988.

This research was supported by National Institutes of Health Grants EY06390, EY07411, and EY03039 (CORE). We would like to thank Cynthia Owsley for comments on an earlier draft of this manuscript. Requests for reprints should be sent to Michael E. Sloane, Department of Psychology, University of Alabama at Birmingham, Birmingham, Alabama 35294. varied (see Grossberg, 1980; Harris \& Gibson, 1968; Kruger, 1979; McCollough, 1965; Stromeyer, 1978), but all have in common the adaptation of feature-specific neurons. More global elements such as the vectorfields postulated by Hoffman's Lie transformation group model of neuropsychology (Dodwell, 1983; Hoffman, 1966, 1978) have recently been suggested as potential mediators of contingent AEs (see, Cavill \& Robinson, 1976; Dodwell, 1984; Dodwell \& O'Shea, 1987; Emerson, Humphrey, \& Dodwell, 1985; Humphrey, Dodwell, \& Emerson, 1985).

As research on the ME expanded, it was noticed that certain ME characteristics were similar to those of an associative learning paradigm. These included generalization, extinction, spontaneous recovery, and reconditioning (Bonnet, 1975; Murch, 1976; Westbrook \& Harrison, 1984); long-term persistence (Jones \& Holding, 1975); and findings that AE magnitude varied in a manner consistent with well-established CS-UCS interval effects in conditioning (Murch, 1976; Schmidt, Pinette, \& Finke, 1978). Promoters of associative models have also argued that, given the wide variety of contingent AEs, it is unlikely that the visual system has compound detectors sensitive to both color and a variety of other stimulus dimensions. Simply stated, the associative learning explanation of MEs is that the lined grid presented in the inspection period serves as the CS, while the color serves as the UCS, which gives rise to UCR-namely, a negative color AE. As a result of the pairing of the CS and UCS, a CR develops. The $\mathrm{CR}$ is in the form of a negative color $\mathrm{AE}$, which can be elicited by subsequent presentation of the CS (achromatic test pattern) alone. It is important to bear in mind, as Skowbo (1986) pointed out, that although certain characteristics of MEs may be similar to those of con- 
ditioning, this does not imply that MEs are actually CRs. This same caveat about functional similarity is equally applicable to neural adaptation models.

While Murch (1976) proposed the first formal associative model of the ME, couched in traditional Pavlovian terminology, more recent studies advocating a learning model have focused on more parametrically precise models of Pavlovian conditioning, such as the RescorlaWagner theory (Rescorla \& Wagner, 1972). This theory holds that the mere pairing of the CS and US is a necessary, but not a sufficient, condition for altering associative strength. The theory provides specific predictions about the associative strength of CS-US pairs when two or more CSs are conditioned to the same US separately, and subsequently paired with the same US. For example, a CS paired with a US that is already well-predicted by another CS will not gain associative strength when the two CSs are presented in compound conditioning. The basic equation for a two-component $(\mathrm{A}, \mathrm{B})$ condition experiment is:

$$
\Delta V=\alpha \beta\left(\lambda-V_{t}\right)
$$

Delta $V$ is the change in associative strength $(V)$ for a given stimulus component present on that trial. Alpha is a learning rate parameter associated with a given CS component. Beta is a learning rate parameter associated with a given US. Lambda is the theoretical asymptote associated with a given US. $V_{t}$ is the sum of associative strength of all components present on the trial. The theory assumes that all stimulus components compete for a share of the total amount of associative strength available for a given US.

In Experiment 1 in the present study, we test predictions of the Rescorla-Wagner theory for the ME by using an "overprediction" paradigm (Rescorla, 1970); in Experiment 2, we test predictions of the Rescorla-Wagner theory by using a "blocking" paradigm (Kamin, 1969). In both cases, the magnitude of ME is an index of associative strength. Overprediction occurs when two components are separately conditioned until each one is close to its asymptotic response level. Then the components are presented in a compound, paired with the same US as before. Following the compound conditioning, the associative strength is measured for each component separately and is found to be reduced relative to precompound levels. Blocking occurs when prior conditioning to one component impairs the subsequent conditioning of a second component presented in compound with the first (Kamin, 1969). Both paradigms predict seemingly counterintuitive results, in light of the literature on visual adaptation. In the case of overprediction, the theory suggests that the magnitude of an $\mathrm{AE}$ will decrease, despite the continued presence of the adapting stimulus in the compound. In the case of blocking, the theory suggests that $\mathrm{AE}$ magnitude, measured for one component of a compound adapting stimulus, will be less if there has been prior adaptation to the other component, even though the two conponents are processed by supposedly independent sets of neurons.
It was our intention to design experimental conditions for generating MEs that allowed us to examine the specific predictions of the Rescorla-Wagner theory for the overprediction and blocking paradigms.

\section{EXPERIMENT 1}

In the overprediction paradigm each component (CS) is initially conditioned separately to a single US. A reduction in associative strength for each component is predicted to follow pairing of the compound with the US. Couched in terms of the parameters set out in Equation 1, each component is initially conditioned separately, such that the $V$ for each is close to $\lambda$. Thus, when the components are later presented in compound, $V_{t}$ (i.e., $V_{a}+V_{b}$ ) will be much larger than $\lambda$, yielding a decrement in associative strength. (For example, if both components have reached asymptote, $V_{t}$ will be twice $\lambda$.) The theory therefore predicts that there will be a loss in associative strength, even though the CSs continue to be paired with the US. Both Rescorla (1970) and Kremer (1978) have provided strong evidence for such a loss in associative strength, though St. Clair-Smith and Mackintosh (1974) failed to replicate the results of the earlier report.

We established the conditions for overprediction in terms of generating MEs as follows. The first component $\left(C S_{1}\right)$ was composed of the traditional horizontal and vertical gratings, paired with magenta and green, respectively. The second component $\left(\mathrm{CS}_{2}\right)$ was composed of right-diagonal and left-diagonal gratings, paired with magenta and green, respectively. The compound stimuli $\left(\mathrm{CS}_{1} / \mathrm{CS}_{2}\right)$ were superimpositions of vertical and leftdiagonal gratings paired with green, and horizontal and right-diagonal gratings paired with magenta. A reduction in $\mathrm{AE}$ magnitude is predicted for both diagonal and horizontal-vertical test patterns when they are measured separately after inspection of the compound stimuli.

\section{Method}

Subjects. Forty undergraduate students (16 male, 24 female) volunteered to participate in this experiment in order to satisfy a course research requirement. The subjects had no prior knowledge of, or experience with, the ME. All subjects were screened for color vision deficiencies using the Dvorine pseudo-isochromatic color plates. Error-free performance on this test served as the inclusion criterion.

Apparatus and Stimuli. The inspection patterns subtended a visual angle of $7.96^{\circ}$ at the $213-\mathrm{cm}$ viewing distance. They consisted of high contrast square-wave gratings of $4.61 \mathrm{cpd}$. They were displayed on a white screen, using two Kodak Ektagraphic projectors (Model III AT). The orientation of the gratings was $0^{\circ}, 45^{\circ}$, $90^{\circ}$, or $135^{\circ}$, which will henceforth be described as horizontal $(\mathrm{H})$, right-diagonal (RD), Vertical (V), and left-diagonal (LD), respectively. In addition, there were two compound patterns, one composed of the superimposition of $H$ and $R D$ gratings (H/RD), and the other composed of $V$ and LD gratings (V/LD). The compound stimuli were not optical superimpositions of the constituent gratings; they were made by combining photographic gratings in a single slide. This method was chosen for practical reasons, although it is theoretically less desirable because new two-dimensional Fou- 
rier fundamentals of lower spatial frequency are introduced at orientations of $22.5^{\circ}$ and $112.5^{\circ}$. The $\mathrm{V}, \mathrm{LD}$, and $\mathrm{V} / \mathrm{LD}$ stimuli were projected through a green filter (Kodak Wratten No. 53), which was affixed to the zoom lens of one projector [henceforth $V_{g}, L_{g}$, and $\left.(\mathrm{V} / \mathrm{LD})_{\mathrm{g}}\right]$. The $\mathrm{H}, \mathrm{RD}$, and $\mathrm{H} / \mathrm{RD}$ inspection stimuli were projected through a magenta filter (Kodak Wratten No. 32) attached to the zoom lens of the second projector [henceforth $H_{m}, R D_{m}$, and $\left.(\mathrm{H} / \mathrm{RD})_{\mathrm{m}}\right)$ ]. The space average luminances (in $\mathrm{cd} / \mathrm{m}^{2}$ ) for the inspection stimuli were $\mathrm{H}_{\mathrm{m}}=73.75, \mathrm{~V}_{\mathrm{g}}=50.60, \mathrm{RD}_{\mathrm{m}}=67.57$, $\mathrm{LD}_{\mathrm{g}}=51.00,(\mathrm{H} / \mathrm{RD})_{\mathrm{m}}=35.67$, and $(\mathrm{V} / \mathrm{LD})_{\mathrm{s}}=24.08$, as measured by a Tektronix $\mathrm{J} 16$ photometer with a $1^{\circ}$ luminance probe.

The angular subtense and spatial frequency of the test patterns were identical to those of the inspection patterns. A schematic of the two test patterns occurs in Figure $1 \mathrm{~b}$. Since the construction and presentation of the two test slides $\left(H_{V_{\text {test }}}\right.$ and $\left.\mathrm{D}_{\text {test }}\right)$ were identical, we will describe only the $\mathbf{H}_{\text {test }}$. The method is quite similar to that of Riggs, White, and Eimas (1974). Portions of the test slide having $\mathrm{H}$ and $\mathrm{V}$ stripes were covered with polarizing filters, oriented in orthogonal directions such that the direction of polarization was orthogonal for adjacent quadrants. The test slides were projected using a Kodak Ektographic (Model AF-2) 35-mm slide projector. At a position corresponding to the focal plane of the projector light source, a rotatable screen target mount (Ealing 22-8767) was mounted orthogonal to, and centered on, the light beam. The beam passed through multiple strips of green (Kodak Wratten No. 53) and magenta (Kodak Wratten No. 32) filters. Each piece of gelatin color filter was covered with a polarizing light filter, with the polarizing material mounted in orthogonal directions for the two colors. Between the strips of combined color and polarizing filters were clear apertures. The net effect was to project the test pattern with a mixture of green, magenta, and white light. The optimal width of the clear aperture was determined in pilot work, and the resultant range of color saturation optimized the range of colorimeter settings for generation of the ME in the formal experiments. By rotating the colorimeter, one could adjust the relative amounts of green and magenta in the $\mathrm{H}$ and $\mathrm{V}$ parts of the test pattern. At one extreme, the horizontal stripes received only magenta and white, while the vertical stripes received only green and white light. At the other extreme, the colors were reversed for the striped patterns. Between these extremes, a position could be found in which green and magenta were mixed in any desired proportion. Though the spectral composition of the test quadrants changed with rotation of the polarizer, there were only minor changes in luminance. Within each quadrant of the $\mathrm{H}-\mathrm{V}$ test pattern, the mean luminance $\left(34.30 \mathrm{~cd} / \mathrm{m}^{2}\right)$ did not change by more than $4.45 \mathrm{~cd} / \mathrm{m}^{2}$. This was also the upper limit of luminance differences between test quadrants. These differences are most likely due to the transmission characteristics of the Wratten filters used. The same variations were found in the diagonal test pattern, whose mean luminance was measured to be $41.16 \mathrm{~cd} / \mathrm{m}^{2}$.

In the absence of a color $\mathrm{AE}$, a null position could be found such that quadrants appeared matched and achromatic. In the presence of a color $\mathrm{AE}$, however, this null point would no longer appear achromatic, and the colorimeter setting would be adjusted so that more green was added to one set of stripes and more magenta to the other. The direction and extent of rotation required to make the test patterns appear achromatic was taken as an index of the magnitude of the color AE. (This cancellation procedure assumes that the test color is exactly complementary to the AE colors. In keeping with most previous research on MEs, no special procedures were introduced to ensure strict fulfillment of this requirement in the present experiments.) During testing, the experimenter very gradually rotated the colorimeter from a random position yielding saturated colors, towards decreasing saturation (i.e., towards the null position). The subject's task was to inform the experimenter when all portions of the test pattern seemed to be colorless. The subject could not see the calibrated dial on the colorimeter. The experimenter read this position off the calibrated dial and rotated the colorimeter to a randomly chosen position yielding saturated colors of the opposite hue (i.e., the subject's null point was approached from both directions). The average of four measures was taken as the subject's setting for each of the two test patterns.

Procedure. Following satisfactory completion of the Dvorine color test, the subjects adapted themselves to the darkened testing room for $5 \mathrm{~min}$. During all inspection and test periods, the subjects viewed the stimuli while using a chin- and headrest to minimize head movements. The task was explained to the subjects, who were subsequently given practice at finding the null point. When the subjects showed good consistency in making these settings, the experiment was begun. Each subject was randomly assigned to one of four groups, each group having 10 subjects. The temporal course of the experiment, which was identical for all groups, is illustrated schematically in Figure 1a. After the practice session, the first test sequence occurred; these measurements served as each subject's baseline. A 3-min dark interval proceeded each test sequence. Measures on $\mathrm{HV}_{\text {test }}$ and $\mathrm{D}_{\text {test }}$ were taken alternately.

Phase 1 (P1) consisted of an initial 15-min inspection period; a test; a 5-min inspection period; a test; another 5-min inspection period; a final test. (The multiple tests were introduced to assess whether the AE had reached a saturation level.) Phase 2 (P2) consisted of a 15-min inspection period followed by a test. Figure 1c schematically illustrates the stimuli being inspected in P1 and P2 for each of the four groups.

In the element-element (E-E), element-compound (E-C), and element-blank (E-B) conditions, the subjects inspected the patterns for a total of $25 \mathrm{~min}$ in P1. Each pattern was presented for $10 \mathrm{sec}$ in the sequence shown $\left(H_{m}, V_{g}, R D_{m}\right.$, and $\left.L D_{g}\right)$. In the compoundcompound $(\mathrm{C}-\mathrm{C})$ condition, the $(\mathrm{H} / \mathrm{RD})_{\mathrm{m}}$ and $(\mathrm{V} / \mathrm{LD})_{\mathrm{g}}$ slides were alternated every $10 \mathrm{sec}$, also for a total of $25 \mathrm{~min}$ in P1. For P2, the E-E group continued to get the same sequence of stimuli as in $\mathrm{P} 1$; the $\mathrm{E}-\mathrm{B}$ group received no stimulation (they remained seated in a darkened room); the $\mathrm{E}-\mathrm{C}$ group received the compound stimuli, again alternating every $10 \mathrm{sec}$; and the $\mathrm{C}-\mathrm{C}$ group continued to get the same alternating compound stimuli as in $\mathrm{Pl}$.
$\Delta$

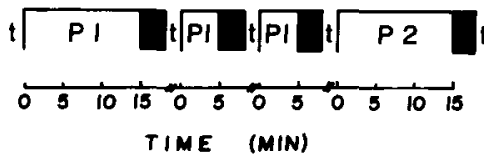

B

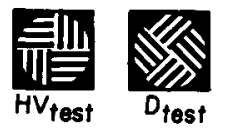

c

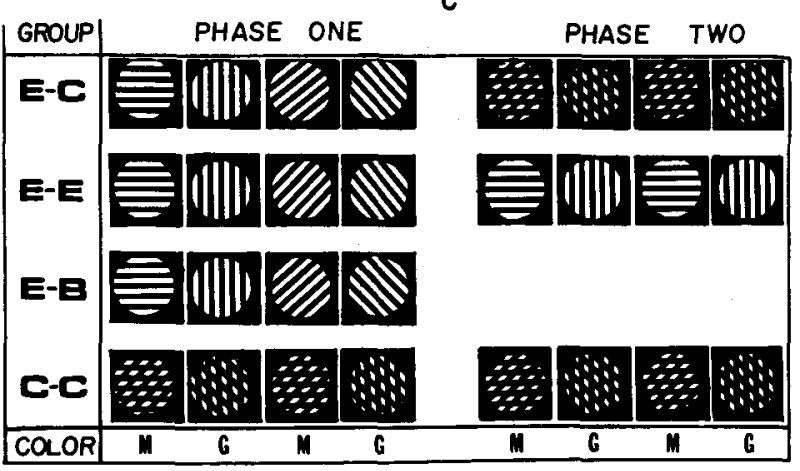

Figure 1. (A) Schematic of time course of inspection in P1 and $P 2$ (the dark blocks denote rest intervals prior to testing). (B) The test stimuli. (C) Schematic of the inspection stimuli for a 40-sec sequence in each phase of Experiment 1. 
Table 1

Three-Way Analysis of Variance on AE Difference Scores (Experiment 1)

\begin{tabular}{|c|c|c|c|c|c|}
\hline Source & $\begin{array}{c}\text { Difference } \\
\text { Scores } \\
\end{array}$ & $d f$ & Ms & $\boldsymbol{F}$ & $p$ \\
\hline \multicolumn{6}{|c|}{ Between Groups } \\
\hline $\begin{array}{l}\text { Conditions } \\
\text { Error }\end{array}$ & $\begin{array}{r}692.8174 \\
1390.0957\end{array}$ & $\begin{array}{r}3 \\
36\end{array}$ & $\begin{array}{r}230.9391 \\
38.6138\end{array}$ & 5.981 & .0024 \\
\hline \multicolumn{6}{|c|}{ Within Groups } \\
\hline $\begin{array}{l}\text { Test pattern } \\
\text { Conditions } \times \text { Test } \\
\text { Error }\end{array}$ & $\begin{array}{r}385.2759 \\
14.9243 \\
327.2433\end{array}$ & $\begin{array}{r}1 \\
3 \\
36\end{array}$ & $\begin{array}{r}385.2759 \\
4.9748 \\
9.0901\end{array}$ & $\begin{array}{r}42.384 \\
0.547\end{array}$ & $\begin{array}{l}.0000 \\
\text { n.s. }\end{array}$ \\
\hline $\begin{array}{l}\text { Time } \\
\text { Conditions } \times \text { Time } \\
\text { Error }\end{array}$ & $\begin{array}{l}133.4424 \\
319.7339 \\
270.8168\end{array}$ & $\begin{array}{r}3 \\
9 \\
108\end{array}$ & $\begin{array}{r}44.4808 \\
35.5260 \\
2.5076\end{array}$ & $\begin{array}{l}17.739 \\
14.168\end{array}$ & $\begin{array}{l}.0000 \\
.0000\end{array}$ \\
\hline $\begin{array}{l}\text { Test } \times \text { Time } \\
\text { Conditions } \times \text { Test } \times \text { Time } \\
\text { Error }\end{array}$ & $\begin{array}{r}15.9790 \\
15.0684 \\
181.0622\end{array}$ & $\begin{array}{r}3 \\
9 \\
108\end{array}$ & $\begin{array}{l}5.3263 \\
1.6743 \\
1.6765\end{array}$ & $\begin{array}{l}3.177 \\
0.999\end{array}$ & $\begin{array}{l}.0266 \\
\text { n.s. }\end{array}$ \\
\hline Total & 3746.4609 & 319 & & & \\
\hline
\end{tabular}

\section{Results}

For each subject, the mean of the four baseline measures was subtracted from the mean of the four measures in each of the subsequent test sequence. In the element adaptation conditions, the resulting positive values for the difference scores indicate the presence of a negative chromatic $\mathrm{AE}$ with larger numbers, indicating stronger AEs. In cases involving compound adaptation, positive values also indicate negative chromatic AEs relative to the cardinal orientation in the compound pattern. For example, a greenish $\mathrm{AE}$ on the horizontal component of the $\mathrm{HV}_{\text {test }}$ would be indexed positively following adaptation to $(H / R D)_{m}$. The difference scores were analyzed using a
4 (conditions: E-C, E-E, E-B, and C-C) $\times 2$ (test pattern: $H V_{\text {test }}$ and $\left.D_{\text {lest }}\right) \times 4$ (inspection time: $15,20,25$, and $40 \mathrm{~min}$ ) three-way analysis of variance. Pertinent planned comparisons were also carried out. The results of this analysis are presented in Table 1.

The average difference scores for each group are presented in Figure 2 as a function of inspection time for each test pattern separately. All three main effects were significant. The data for the three element conditions in Pl revealed no differences in AE magnitude for either test pattern following any of the P1 inspection periods. AE magnitude was significantly larger for the three element conditions than for the compound condition.
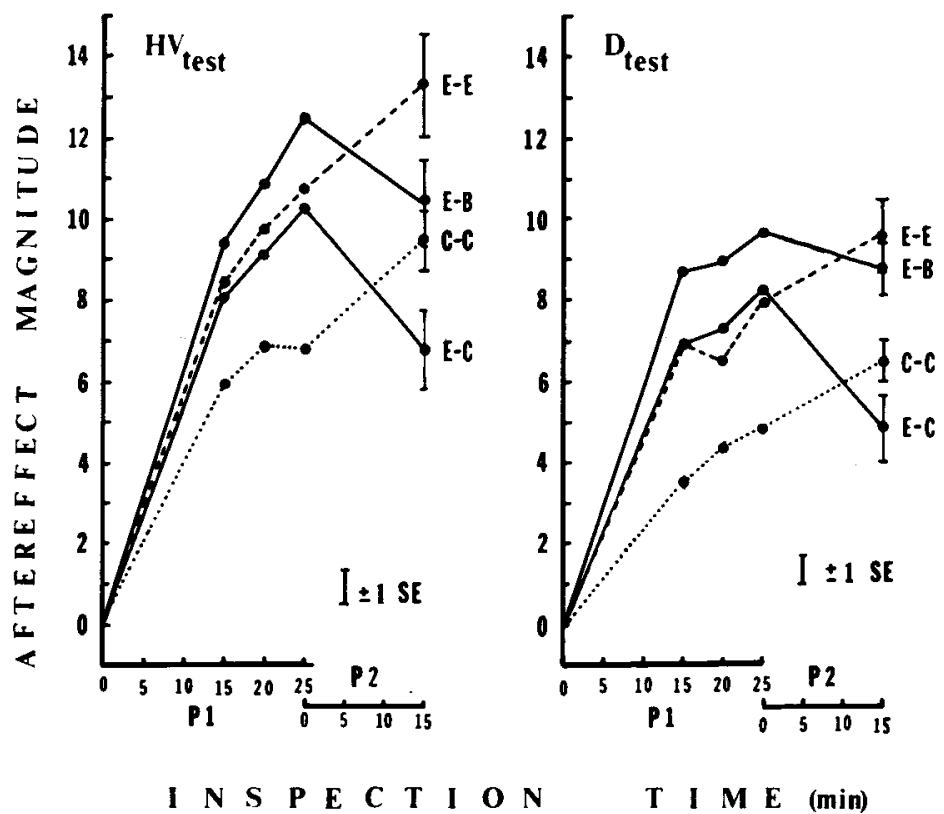

Figure 2. Aftereffect magnitude measured for the $H V_{\text {teat }}$ (left) and $D_{\text {teat }}$ are shown as a function of cumulative inspection time for the four conditions in Experiment 1. 
The comparisons of most interest, however, occur in the $P 2$ data. There was a significant conditions $\times$ inspection time interaction. Further analysis of this interaction indicated that the effect of inspecting the P2 stimuli differed among the groups $[F(3,36)=11.37$, $p<.0001]$. There was no conditions $\times$ inspection time interaction for $\mathrm{P} 1$ data alone $(p>.95)$. The overprediction hypothesis that condition $\mathrm{E}-\mathrm{C}$ would show a larger decrease relative to E-B following inspection of compound stimuli was supported $[F(1,36)=7.325, p=.01]$. Examination of the E-C versus E-B comparison for the test patterns individually showed that the prediction was supported for $\mathrm{D}_{\text {test }}[F(1,36)=6.20, p=.016]$, but only marginally supported for $\mathrm{HV}_{\text {test }}[F(1,36)=2.97$, $p=.0897]$. The only between-groups comparison which did not show a significant effect of P2 inspection was that between the $\mathrm{E}-\mathrm{E}$ and $\mathrm{C}-\mathrm{C}$ conditions. Both these functions continued to rise at the same rate with continued inspection of the same stimuli. As was seen in P1, AEs measured in the $\mathrm{C}-\mathrm{C}$ condition were significantly smaller than those in the E-E condition.

The inspection time $\times$ test pattern interaction was significant. AE magnitude for the $\mathrm{D}_{\text {test }}$ pattern was typically weaker, and it increased at a slower rate than for the $\mathrm{HV}_{\text {test }}$. However this interaction did not differ across conditions. Neither the conditions $\times$ test pattern nor the threeway interaction was significant.

\section{Discussion}

The data from Experiment 1 support the overprediction hypothesis as formulated by the Rescorla-Wagner theory. For overprediction to occur optimally, the associative strength of the individual components should be close to the asymptotic level prior to simultaneous compound conditioning. In Figure 2 we see that the AE magnitude at the end of $P 1$, when compared to the final measure in the E-E condition, was reasonably close to asymptotic levels. This suggests that the values of $V_{a}$ and $V_{b}$ were approaching $\lambda$; therefore, in the $\mathrm{E}-\mathrm{C}$ (overprediction) condition, their sum was well in excess of $\lambda$. Thus, a decrease in associative strength ( $\mathrm{AE}$ magnitude) would be predicted.

How could a neural adaptation model account for the larger decrease in $\mathrm{AE}$ magnitude in the $\mathrm{E}-\mathrm{C}$ condition than in the E-B condition? One would have to posit some mechanism whereby the effects of prior adaptation were negated at a faster rate than the normal decay function. Even if observers in the E-C condition perceived the compound stimulus as novel and if the magnitude of the ME was determined by the perceptual appearance of the induction pattern-which Green, Corwin, and Zemon (1976) and May and Mapperson (1976) argue it is notthen the $\mathrm{AE}$ magnitude should have been equivalent to that in the E-B condition. The data do not support this interpretation. The compound adaptation stimuli, as mentioned previously, contain Fourier fundamental components at orientations of $22.5^{\circ}$ and $112.5^{\circ}$. For the $(\mathrm{H} / \mathrm{RD})_{\mathrm{m}}$ pattern, the fundamental at $22.5^{\circ}$ is closer in frequency to the cardinal component grating, while for the $(\mathrm{V} / \mathrm{LD})_{\mathrm{g}}$ pattern, the component at $112.5^{\circ}$ is closer in frequency. With alternating adaptation to these compound stimuli, the major and minor Fourier components at both orientations are coupled with both magenta and green, which may or may not lead to a cancellation effect. The Fourier component closer in orientation to the cardinal component of the compound is also the one closer in spatial frequency, but, given the poor spatial frequency selectivity of the ME, this is unlikely to bestow any advantage. To account for the difference between E-B and $\mathrm{E}-\mathrm{C}$ found in the present experiment, one would have to argue that the Fourier component closer in orientation to the cardinal component, while being paired with both green and magenta, is more effective when paired with the color complementary to that with which the cardinal component was paired. This might then serve to weaken the AE measured after compound adaptation. It must be pointed out that inspection of the compound stimuli in P1 (see C-C) could generate substantial color AEs contingent on the orientation of the compound components $(H$, $\mathrm{RD}, \mathrm{V}, \& \mathrm{LD}$ ), although these effects were significantly smaller than when the components were alternated individually (see Figure 2).

The finding of reduced AEs with compound induction stimuli is not novel, nor is it uniquely predicted by the associative learning or visual adaptation models. Brand, Holding, and Jones (1987) found diminished AEs following compound inspection, relative to the AEs measured when the compound components were viewed alone, while Westbrook and Harrison (1984) found no decrements. One argument that has been offered to explain such decrements is that the effective conditioning stimulus in the compound condition is the configuration, or gestalt percept, of the stimuli rather than the sum of two individual components (Mackintosh, 1975; St. Clair-Smith $\&$ Mackintosh, 1974). Also, the parameter $\beta$ in Equation 1 is affected by factors such as US intensity, and since the space average luminance of the compound stimuli was lower than that of the element stimuli, the RescorlaWagner theory would predict smaller effects in the C-C condition. Reduced AEs in the C-C condition would also be predicted on the basis of the literature on visual adaptation. Luminance, contrast, and color saturation are known to affect ME magnitude (Ellis, 1976; Shute, 1979; White, 1976). Note, however, that since there were only two compound stimuli alternating in the $\mathrm{C}-\mathrm{C}$ condition, the total exposure time for each was twice that for the individual stimuli in the element conditions. One could also propose that the pairing of the Fourier components with both colors did not lead to mutual cancellation, but instead yielded more potent effects for the color complementary to that with which the cardinal component was paired. Smaller AEs following adaptation to compound stimuli have been explained in terms of disinhibition, wherein the presence of component $A$ in a compound adaptation may serve to weaken the AEs generated by component B (see Kurtenbach \& Magnussen, 1981; 
Levinson \& Sekuler, 1975a, 1975b; Magnussen \& Kurtenbach, 1980a, 1980b). It is unclear, however, how the presence of inhibition or disinhibition in the E-C condition in $\mathrm{P} 2$ would reduce the $\mathrm{AE}$ magnitude relative to that in the E-B condition. Brand et al. (1987) suggested that the superimposition of gratings introduces visual geometric distortions of the Zöllner and/or Poggendorf type. The very broad orientation tuning of the ME (Ellis, 1976) and the finding that the color AEs can also be contingent on the perceived orientation of the test stimuli (Mikaelian, 1976) weaken this argument.

It is not clear why there was an overall effect of test pattern. The difference between the two test patterns was similar in the compound and three element conditions in $P 1[F(3,36)=0.27, p>0.84]$, which suggests that the stimuli were of equivalent salience. An asymmetry in lateral inhibition could yield consistently smaller AEs for the latter (Carpenter \& Blakemore, 1973).

\section{EXPERIMENT 2}

In terms of the Rescorla-Wagner theory, prior inspection of one component, such that the associative strength reaches an asymptote, will prevent an increase in associative strength of the other component. Thus, in Equation 1, $V_{\mathrm{t}}=\left(V_{\mathrm{a}}+V_{\mathrm{b}}\right)$ would be close, or equal, to $\lambda$, since, with prior conditioning of one component, either $V_{a}$ or $V_{b}$ would be close to its asymptote. Hence there would be no increase in total associative strength to the second component, resulting in a reduced $\mathrm{AE}$ for that component. For example, prior inspection of the HV component before inspection of the compound should serve to reduce the AE measured on $D_{\text {test }}$, relative to the $A E$ measured in a condition where there was no prior exposure to either component before the inspection of the compound stimuli.

Although not following traditional methodology for the generation of the ME, Westbrook and Harrison (1984) found evidence for blocking, as did Siegal and Allan (1985), who used a paradigm more typical for the generation of MEs. In the latter study, the diagonal stimuli were more salient than the horizontal-vertical stimuli, as evidenced by their overshadowing results; thus, blocking in only one direction was obtained. However, bidirectional blocking has been found using components differing in salience (Brand et al., 1987). In the present experiment we used components that were equally salient (according to the results of Experiment 1); therefore bidirectional blocking was expected.

\section{Method}

Subjects. Forty undergraduate students ( 9 male, 31 females) participated in Experiment 2 to satisfy a course research requirement. The male-female ratio was roughly equivalent across experimental groups. No subject had participated in Experiment 1 or had any familiarity with the ME. As before, none of these subjects had any color deficiency as assessed by the Dvorine plates.

Apparatus and Stimuli. The apparatus and the spatial characteristics of the inspection and test stimuli were the same as in Experiment 1, except for one change. In Experiment 1, a few sub- jects noticed that they could not find a neutral point where the test stimuli were completely colorless. This is most likely due to the difference in percent transmission of Kodak Wratten filters Nos. 53 and 32. The result is a luminance difference when magenta and green are projected on the screen, which could, in tum, lead to color AEs of different strength. Riggs et al. (1974) attempted to compensate for this problem, but most investigators have ignored it. In Experiment 2, we equalized the luminance of the projected magenta and green patterns by using neutral density filters. The space average luminance for the inspection patterns expressed in $\mathrm{cd} / \mathrm{m}^{2}$ were: $H_{m}$ $=18.59, \mathrm{~V}_{\mathrm{g}}=19.69, \mathrm{RD}_{\mathrm{m}}=19.62, \mathrm{LD}_{\mathrm{z}}=19.31,(\mathrm{H} / \mathrm{RD})_{\mathrm{m}}$ $=10.15$, and $(\mathrm{V} / \mathrm{LD})_{\mathrm{g}}=10.19$.

Procedure. There were four conditions, with 10 subjects randomly assigned to each one. The temporal course of inspection and testing was the same for each condition. It was different from the previous experiment, in that one of the 5-min periods of P1 inspection was dropped. All groups therefore had an initial (baseline) test; $15 \mathrm{~min}$ of P1 inspection; a test; 5 min of P1 inspection; a test; 15 min of $P 2$ inspection; a final test. Figure 3 schematically illustrates a 20-sec sample of $P 1$ and $P 2$ inspection stimuli for each of the four conditions (HV-C, D-C, MG-C, and W-C). Each test, as before, was proceeded by a 3-min dark interval. Since all groups inspected the $(\mathrm{H} / \mathrm{RD})_{\mathrm{m}}$ and $(\mathrm{V} / \mathrm{LD})_{\mathrm{g}}$ compound stimuli in $\mathrm{P} 2$, the stimuli seen during the 20 -min $P 1$ inspection period differentiated the groups. The stimuli were alternated every $10 \mathrm{sec}$ as in Experiment 1. In P1, the HV-C group saw $H_{m}$ and $V_{g}$; the D-C group saw $\mathrm{RD}_{\mathrm{m}}$ and $\mathrm{LD}_{\mathrm{s}}$; the MG-C group saw homogeneous color stimuli of magenta (mean luminance $=34.71 \mathrm{~cd} / \mathrm{m}^{2}$ ) and green $\left(34.19 \mathrm{~cd} / \mathrm{m}^{2}\right)$. The $\mathrm{W}-\mathrm{C}$ group saw homogeneous white stimuli $\left(35.74 \mathrm{~cd} / \mathrm{m}^{2}\right)$.

\section{Results}

The difference scores, as defined previously, are plotted separately for the $\mathrm{D}_{\text {test }}$ and $\mathrm{HV}_{\text {test }}$ patterns for the four conditions, as a function of inspection time, in Figure 4. The difference scores were analyzed by using a 4 (conditions: HV-C, D-C, MG-C, and W-C) $\times 2$ (test pattern: $D_{\text {test }}$ and $H V_{\text {test }}$ ) $\times 3$ (inspection time: 15,20 , and $35 \mathrm{~min}$ ) three-way analysis of variance. Pertinent planned

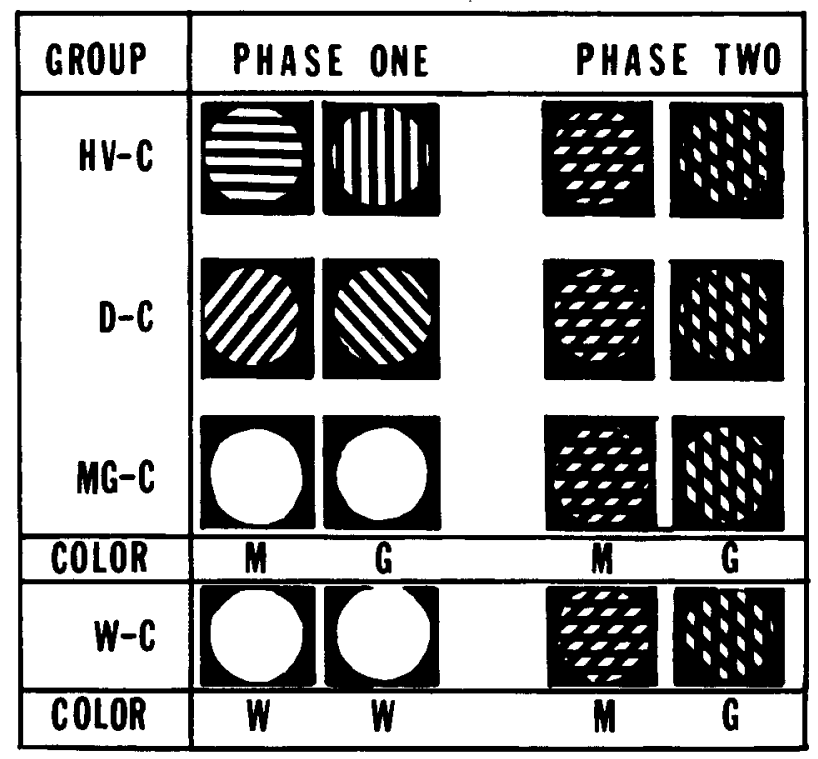

Figure 3. Schematic of inspection stimuli for a $20-\mathrm{sec}$ sequence of $P 1$ and $P 2$ for each of the four conditions in Experiment 2. 

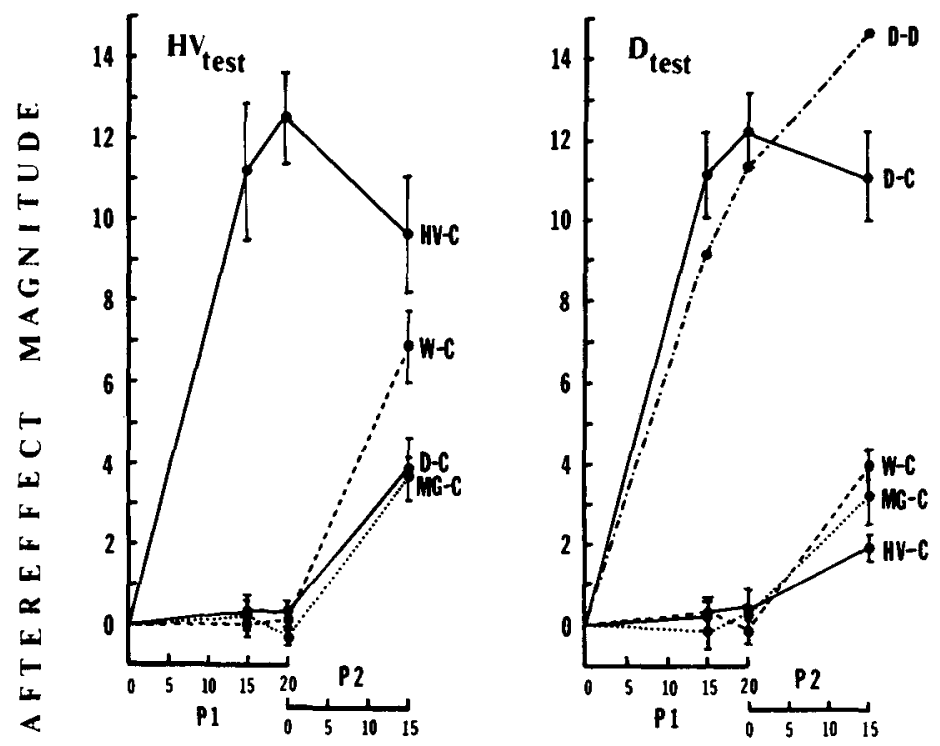

$$
\begin{array}{lllllllllllllll} 
& \mathbf{N} & \mathbf{S} & \mathbf{P} & \mathbf{E} & \mathbf{C} & \mathbf{T} & \text { I } & \mathbf{O} & \mathbf{N} & \mathbf{T} & \text { I } & \mathbf{M} & \mathbf{E} & \text { (min) }
\end{array}
$$

Figure 4. Afterefiect magnitude measured for the $H V_{\text {teat }}$ (left) and $D_{\text {teat }}$ (right) as a function of cumulative inspection time in Experiment 2.

comparisons were also carried out. The results are given in Table 2.

With respect to the P1 data in Figure 4, the most obvious and predictable finding is the large AE for the test pattern for which there had been prior inspection. No orientation-contingent AEs were found following inspection of white light or alternating homogeneous colors (W-C and MG-C conditions). Likewise no AEs were found for the test patterns whose orientations had not been previously seen. These conditions did not differ significantly from each other or from baseline measures $(p>$.92). Phase 2 inspection of the compound stimuli differentially affected the conditions when $\mathrm{AE}$ was measured for both $\mathrm{HV}_{\text {test }}[F(3,36)=45.36, p<.0001]$ and $D_{\text {test }}[F(3,36)=12.08, p<.0005]$.
The crucial comparisons in the context of the blocking paradigm are those (1) between $\mathrm{AE}$ magnitude for $\mathrm{HV}_{\text {test }}$ in the D-C and in the W-C conditions, and (2) between AE magnitude for $D_{\text {test }}$ in the $\mathrm{HV}-\mathrm{C}$ and in the W-C conditions. The aftereffect on $\mathrm{HV}_{\text {test }}$ was significantly smaller $[F(1,36)=14.01, p<.001]$ in the $\mathrm{D}-\mathrm{C}$ condition. In other words, prior inspection of the $\mathrm{RD}_{\mathrm{m}}$ and $\mathrm{LD}_{\mathrm{g}}$ before inspection of the compound stimuli served to reduce or block the growth of the aftereffect for $\mathrm{HV}_{\text {test }}$, relative to the aftereffect for $\mathrm{HV}_{\text {test }}$ found when there was no prior inspection of compound components (i.e., the W-C condition). Similarly, the AE for the $\mathrm{D}_{\text {test }}$ pattern in the HV-C condition was smaller than that measured in the W-C condition $[F(1,36)=7.56, p<.01]$. Bidirectional blocking was therefore obtained.

Table 2

Three-Way Analysis of Variance on AE Difference Scores (Experiment 2)

\begin{tabular}{|c|c|c|c|c|c|}
\hline Source & $\begin{array}{c}\text { Difference } \\
\text { Scores }\end{array}$ & $d f$ & $M$ s & $\boldsymbol{F}$ & $p$ \\
\hline \multicolumn{6}{|c|}{ Between Groups } \\
\hline $\begin{array}{l}\text { Conditions } \\
\text { Error }\end{array}$ & $\begin{array}{r}1375.8596 \\
522.3936\end{array}$ & $\begin{array}{r}3 \\
36\end{array}$ & $\begin{array}{r}458.6199 \\
14.5109\end{array}$ & 31.605 & .0000 \\
\hline \multicolumn{6}{|c|}{ Within Groups } \\
\hline $\begin{array}{l}\text { Test pattern } \\
\text { Conditions } \times \text { Test } \\
\text { Error }\end{array}$ & $\begin{array}{r}4.5337 \\
3085.5359 \\
452.8647\end{array}$ & $\begin{array}{r}1 \\
3 \\
36\end{array}$ & $\begin{array}{r}4.5337 \\
1028.5120 \\
12.5796\end{array}$ & $\begin{array}{r}0.360 \\
81.760\end{array}$ & $\begin{array}{l}\text { n.s. } \\
.0000\end{array}$ \\
\hline $\begin{array}{l}\text { Time } \\
\text { Conditions } \times \text { Time } \\
\text { Error }\end{array}$ & $\begin{array}{l}333.6005 \\
243.7674 \\
159.1224\end{array}$ & $\begin{array}{r}2 \\
6 \\
72\end{array}$ & $\begin{array}{r}166.8002 \\
40.6279 \\
2.2100\end{array}$ & $\begin{array}{l}75.474 \\
18.383\end{array}$ & $\begin{array}{l}.0000 \\
.0000\end{array}$ \\
\hline $\begin{array}{l}\text { Test } \times \text { Time } \\
\text { Conditions } \times \text { Test } \times \text { Time } \\
\text { Error }\end{array}$ & $\begin{array}{r}11.7621 \\
134.0781 \\
92.5076\end{array}$ & $\begin{array}{r}2 \\
6 \\
72\end{array}$ & $\begin{array}{r}5.8810 \\
22.3463 \\
1.2848\end{array}$ & $\begin{array}{r}4.577 \\
17.392\end{array}$ & $\begin{array}{l}.0134 \\
.0000\end{array}$ \\
\hline Total & 6416.0293 & 239 & & & \\
\hline
\end{tabular}


There was a reduction in $\mathrm{AE}$ magnitude for the $\mathrm{HV}_{\text {test }}$ in the $\mathrm{HV}-\mathrm{C}$ condition following $\mathrm{P} 2$ inspection $[F(1,36)$ $=22.42, p<.0001$ ], while the reduction in $\mathrm{AE}$ for $\mathrm{D}_{\text {test }}$ in the D-C condition did not reach statistical significance $[F(1,36)=2.97, p=.09]$. This supports the results of Experiment 1. AE magnitude had not saturated at the end of $\mathrm{P} 1$, as indicated by the data for an additional 8 subjects who continued to view the diagonal patterns through P2 (labelled D-D' in Figure 4). There was no main effect for test pattern, but the significant test pattern $\times$ inspection time interaction suggests that the AEs had different growth and decay rates. In addition, there was a smaller $A E$ for $D_{\text {test }}$ than for $H V_{\text {test }}$ in the W-C condition following $\mathrm{P} 2$ viewing $[F(1,36)=12.12, p<.005]$. Finally, AEs in the MG-C condition were smaller, relative to those in the W-C condition $[F(1,36)=7.21, p<.05]$.

\section{Discussion}

Blocking was bidirectional, but this blocking appears to be incomplete, since there were measurable and statistically significant AEs for the compound component to which there was no prior exposure. Partial blocking suggests that the associative strength for the blocking component had not reached asymptote prior to inspection of the compound $\left(V_{\mathrm{a}}<\lambda\right.$ in Equation 1). In previous studies using $\mathrm{AE}$ magnitude in a blocking paradigm that reported either total (Westbrook \& Harrison, 1984) or partial (Siegal \& Allan, 1985) blocking, there was little indication as to how close AE magnitude had come to asymptotic levels. Brand et al. (1987) found total blocking in both directions, which would be expected if indeed the AEs had asymptoted prior to compound inspection; this appears to be the case for the grating component but not for the spiral component (see their Figure 1). Of course, the data for their 5- and 10-min adaptation periods were collected on different observers. Given that the present experiment used a very similar method, it is surprising that Brand et al. found no increase in AE magnitude between these two adaptation periods while AEs in the present study continued to increase in magnitude up to $35 \mathrm{~min}$ (Experiment 2) and $40 \mathrm{~min}$ (Experiment 1). Although AE magnitude for the two components in the Brand et al. study were not equal, blocking was symmetri$\mathrm{cal}$; in the study of Siegal and Allan (1985), the components were clearly different with regard to both their amplitude and frequency spectrum, and this difference in salience resulted in unidirectional blocking effects. In the present study, there was no difference in $\mathrm{AE}$ magnitude at the end of $P 1$ for $\mathrm{HV}_{\text {test }}$ in $\mathrm{HV}-\mathrm{C}$ or for $\mathrm{D}_{\text {test }}$ in D-C $[t(18)=0.12, p>.05]$.

Let us examine the blocking results in terms of visual adaptation. The AE measured for the blocked component in the HV-C and D-C conditions was smaller than the AE for this component in the W-C condition. Since the time of adaptation to this component was equivalent, the change in AE strength had to be a consequence of the prior adaptation history (either to a homogeneous white pattern or to a grating differing in orientation by $45^{\circ}$ ). The block- ing paradigm used here is very similar to a composite adaptation technique employed by Levinson and Sekuler (1975b), who examined threshold elevation AEs for one component (A) following adaptation to either a compound $(A, B)$ or to that compound following prior adaptation to the other component (B). They found that $\mathrm{AE}$ magnitude for component $A$ was larger following the $B-(A, B)$ adaptation sequence than following adaptation to the compound $(A, B)$ alone. This pattern of results was attributed to disinhibition, whereby prior adaptation to component B rendered it less effective in the compound (i.e., reduced its inhibition of A). The blocking results of the present experiment require the reverse effect, namely that prior adaptation to $B$ [in a $B-(A, B)$ condition] reduces the $A E$ measured for $A$ relative to that found following $(A, B)$ adaptation.

Let us consider for a moment the fate of the Fourier components in the compound patterns for the W-C and D-C conditions with regard to $\mathrm{HV}_{\text {test }}$ (a symmetrical argument applies for $\mathrm{D}_{\text {test }}$ across the W-C and $\mathrm{HV}-\mathrm{C}$ conditions). In both the $\mathrm{W}-\mathrm{C}$ and $\mathrm{D}-\mathrm{C}$ conditions, both fundamental Fourier components are paired with both green and magenta, yet the $\mathrm{AE}$ for $\mathrm{HV}_{\text {test }}$ is significantly decreased in the $D-C$ condition relative to the $W-C$ condition. The difference between the two conditions is, of course, the complementary color AEs built up at the $45^{\circ}$ and $135^{\circ}$ orientations. However, these negate each other for an $\mathrm{HV}_{\text {test }}$ pattern, as evidenced by the absence of any $\mathrm{AE}$ for $\mathrm{HV}_{\text {test }}$ at the end of $\mathrm{P} 1$ in the D-C condition. Assuming for a moment that the complementary AEs of the $22.5^{\circ}$ and $112.5^{\circ}$ Fourier components had not cancelled each other, and that there was a more potent AE for the color complementary to that with which the cardinal component was paired, then these residual effects should be severely reduced, or eliminated, by the potent complementary AEs previously generated at $45^{\circ}$ and $135^{\circ}$. We feel, therefore, that an explanation for the results of this experiment couched in terms of the fate of the Fourier fundamental components is weak and strained.

A result that could be explained either by an associative learning approach or by a visual adaptation approach is that the aftereffects for $D_{\text {test }}$ were smaller than for $H V_{\text {test }}$ in the W-C condition. This occurred despite the fact that $P 1$ inspection yielded AEs of equivalent magnitude for $H V_{\text {test }}$ and $D_{\text {test }}$ in the HV and DC conditions, respectively. In addition, the $A E$ for $D_{\text {test }}$ in the HV-C condition was smaller than that for $\mathrm{HV}_{\text {test }}$ in the D-C condition. Both of these findings suggest that the diagonal component was at a disadvantage, or less salient, in the compound stimuli. Salience in the present studies is difficult to characterize, since the components were equivalent in the Fourier domain, and their high contrast rules out simple explanations in terms of meridional difference in contrast sensitivity. The pattern of results could result if one of the components was closer to asymptotic levels of $\mathrm{AE}$ magnitude. In the absence of a second control group (like D-D) that viewed the HV component through P2, we cannot directly address this alternative. As with the previ- 
ous experiment, one could also discuss this result in terms of an asymmetry, in suprathreshold inhibition, between orientation-selective mechanisms during compound adaptation.

Another result that does not lend itself to unique interpretation is that the AEs in the MG-C condition were smaller than those in the $\mathrm{W}-\mathrm{C}$ condition. In an associative learning framework, prior exposure to the US serves to reduce the associative strength resulting from subsequent pairings of CSs with that US. Preexposure to the US is known to have blocking-like effects (see, e.g., Mis \& Moore, 1973) and has previously been noted in the ME literature (Bonnet, 1975; Murch, 1976; Westbrook \& Harrison, 1984). One could also discuss this result in terms of altering the response characteristics of color-opponent neurons, such that the color dimension of subsequently presented orientation-color contingencies would be less effective.

\section{GENERAL DISCUSSION}

As noted in our introduction, explanations of the ME have typically been couched in either conditioning or feature-adaptation terms. This theoretical dichotomy is somewhat arbitrary when one considers the modifiability of operating characteristics required by a visual system that has, as a desired goal, the signalling of covariation among various stimulus dimensions. Adaptation and habituation phenomena reflect an environmentally sensitive coding of signal probability, and they are implemented, in part, by alterations in the operating characteristics of neurons and in the effectiveness of variable synapses. If it is useful for an organism to register what stimulus characteristics change concurrently, it should not be unreasonable to expect to find a neural process that facilitates the registering of stimulus covariations. If stimulus probability is coded by changes in neuronal operating characteristics, one can consider an adaptation $\mathrm{AE}$ as the system's inability to immediately reverse or reset the code for stimulus presence. Simple AEs occur often and have been described as a first-order redundancy (Anstis, 1975). Contingent AEs, involving the pairwise covariation between stimulus dimensions, occur less often and therefore are potentially more informative. The buildup and decay times for contingent AEs are slower than for simple AEs, indicating higher order adaptation (Riggs et al., 1974; see also Favreau, 1979). Barlow (1985) has argued that the main function of the cortex is to note "suspicious coincidences" in its afferent input as a means of gaining knowledge about nonrandom, causally related features of the environment. In the typical induction of the $M E$, we present the rather uncommon pairings of orientations and colors that persist over multiple presentations for a relatively long period of time. The cooccurrence of orientation and colors could be effectively coded by neurons sensitive to both stimulus dimensions, with the subsequent contingent AEs arising from alterations in the operating characteristics of such neurons. Alternatively, the two stimulus dimensions could be processed in separate topographically organized modules with subsequent convergence of neural information.

There are several indications that the site of the ME is at least one step removed from sensory processing in striate cortex. The ME can be obtained long after any measurable threshold elevation for chromatic gratings is found, which suggests that the mechanisms underlying the ME are not those responsible for threshold elevation (Timney, Gentry, Skowbo, \& Morant, 1974). The ME is not localized to retinally adapted areas (Caelli, O'Neill, \& Miller, 1977), and it can also be obtained even in the absence of locally defined orientation-color contingencies (Dodwell \& O'Shea, 1987; see also Emerson et al., 1985). The spatial frequency and orientation specificity of orientation-contingent color AEs are, to a large extent, a by-product of the type of induction and test stimuli typically used. Using a single test orientation, which precludes the color contrast present in the typical test pattern, one can obtain complementary AEs that are largest for the inducting orientation but are also present at orthogonal orientations (MacKay \& MacKay, 1977). All of the above suggests that the site of the ME is removed from the modular preprocessing of stimulus dimensions. This preprocessing is mediated by mechanisms with such a limited range of connectivity as to preclude any assessment of global information. It has been suggested that the results of the local analysis are redistributed to extrastriate areas (perhaps according to nontopographical principles) to facilitate the registering of covariation among stimulus dimensions (Barlow, 1980; Phillips, Zeki, \& Barlow, 1984). Contingent AEs, within such a scheme, could be conceived as resulting from changes in operating characteristics of neurons in these regions. As Grossberg (1980) has pointed out, one does not have to revert to a conditioning type of model to explain the dynamic changes in neuronal operating characteristics subsequent to repeated or prolonged stimulation. Uttley (1979) has elaborated on the formal similarity between models of synaptic variability (during a conditioning paradigm) and the RescorlaWagner theory. Clearly, in explaining the ME in terms of conditioning, one is dealing with a type of conditioning in which the association between the elements is very much constrained by the neural coding and information classification. As has been pointed out, one does not get color AEs contingent on arbitrary patterns (White \& Riggs, 1974), but rather on stimulus dimensions, for which there is a well-defined local and topographic analysis.

In summary, the ability to detect the conjoint presence of different stimulus attributes and their continued copresence is adaptive for the perceiver. The neural mechanisms facilitating this capacity may be removed from the initial, local, topographical analysis of sensory information in striate cortex. The alterations in operating characteristics of mechanisms signalling covariation between stimulus attributes underlie contingent AEs. The dynamics of these alterations may well be formally similar to the characteristics of classical conditioning. 


\section{REFERENCES}

Allan, L., \& Siegel, S. (1986). McCollough effects as conditioned responses: Response to Skowbo. Psychological Bulletin, 100, 388-393.

ANstis, S. M. (1975). What does visual perception tell us about visual coding? In M. S. Gazzaniga \& C. Blakemore (Eds.), Handbook of psychobiology (pp. 269-323). New York: Academic Press.

BARLow, H. B. (1980). Cortical function: A tentative theory and preliminary tests. In D. McFadden (Ed.), Neural mechanisms in behavior (pp. 143-167). New York: Springer-Verlag.

BARLOW, H. B. (1985). Cerebral cortex as model builder. In D. Rose \& V. G. Dobson (Eds.), Models of the visual cortex (pp. 37-46). New York: Wiley.

BoNNET, C. (1975). Le conditionnement sensori-sensoriel dans les analyseurs visuels d'attributs [Sensory-sensory conditioning in analyses of visual attributes]. Psychologie Française, 20, 35-43.

Brand, J. L., Holding, D. H., \& Jones, P. D. (1987). Conditioning and blocking of the McCollough effect. Perception \& Psychophysics, 41, 313-317.

Caelu, T. M., ONeILl, G., \& Miller, J. (1977). Frequency and orientation interactions in the McCollough effect: Interchannel effects? Australian Journal of Psychology, 29, 185-193.

CARPENTER, R. H. S., \& Blakemore, C. (1973). Interactions between orientations in human vision. Experimental Brain Research, 18, 287-303.

Cavill, J., \& Robinson, J. O. (1976). A color aftereffect contingent on complex pattern features. Perception \& Psychophysics, 19, 454-459.

DODWELL, P. C. (1983). The Lie transformation group model of visual perception. Perception \& Psychophysics, 34, 1-16.

DODWELL, P. C. (1984). Local and global factors in figural synthesis. In P. C. Dodwell \& T. M. Caeli (Eds.), Figural synthesis (pp. 219248). Hillsdale, NJ: Erlbaum.

Dodwell, P. C., O'SHEA, R. (1987). Global factors generate the McCollough effect. Vision Research, 27, 569-580.

ELus, S. R. (1976). Orientation selectivity of the McCollough effect: Analysis by equivalent contrast transformation. Perception \& Psychophysics, 22, 539-544.

Emerson, V. F., Humphrey, G. K., \& Dodwell, P. C. (1985). Color aftereffects contingent on patterns generated by Lie transformation groups. Perception \& Psychophysics, 37, 155-162.

Favreau, O. E. (1979). Persistence of simple and contingent motion aftereffects. Perception \& Psychophysics, 26, 187-194.

Green, M., CoRwiN, T. R., Zemon, V. (1976). A comparison of Fourier analysis and feature analysis in pattern-specific color aftereffects. Science, 192, 147-148.

Grossberg, S. (1980). How does a brain build a cognitive code? Psychological Review, 87, 1-51.

HARRIs, C. S. (1980). Insight or out of sight? Two examples of perceptual plasticity in the human adult. In C. S. Harris (Ed.), Visual coding and adaptability (pp. 95-149). Hillsdale, NJ: Erlbaum.

HARris, C. S., \& Gibson, A. R. (1968). Is orientation-specific color adaptation in human vision due to edge detectors, afterimages or "dipoles'? Science, 162, 1506-1507.

Hoffman, W. C. (1966). The Lie algebra of visual perception. Journal of Mathematical Psychology, 3, 65-98.

Hoffman, W. C. (1978). The Lie transformation group approach to visual neuropsychology. In E. L. J. Leuwenberg \& H. Buffart (Eds.), Formal theories of visual perception (pp. 27-66). Chichester, England: Halstead Press.

Humphrey, G. K., Dodwell, P. C., Emerson, V. F. (1985). The roles of pattern orthogonality and color contrast in the generation of pattern-contingent color aftereffects. Perception \& Psychophysics, 38 , 343-353.

JONES, P. D., \& HoLDING, D. (1975). Extremely long-term persistence of the McCollough effect. Journal of Experimental Psychology: Human Perception \& Performance, 1, 323-327.

Kamin, L. J. (1969). Predictability, surprise, attention, and conditioning. In B. A. Campbell \& R. M. Church (Eds.), Punishment and aversive behavior (pp. 279-296). New York: Appleton-Century-Crofts.
KREMER, E. F. (1978). The Rescorla-Wagner model: Losses in associative strength in compound conditioned stimuli. Joumal of Experimental Psychology: Animal Behavior Processes, 4, 22-36.

KRUGER, J. (1979). McCollough effect: A theory based on the anatomy of the lateral geniculate neurons. Experimental Brain Research, 30, 297-311.

Kurtenbach, W., \& Magnussen, S. (1981). Inhibition, disinhibition, and summation among orientation detectors in human vision. Experimental Brain Research, 43, 193-198.

Levinson, E., Sexuler, R. (1975a). The independence of channels in human vision selective for direction of movement. Joumal of Physiology, 250, 347-366.

Levinson, E., \& SEKUler, R. (1975b). Inhibition and disinhibition of direction-specific mechanisms in human vision. Nature, 254, 692-694.

MACKAY, V., \& MACKAY, D. M. (1977). Multiple orientation-contingent chromatic aftereffects. Quarterly Journal of Experimental Psychology, 29, 203-218.

MaCxintosh, N. J. (1975). Blocking of conditioned suppression: Role of the first compound trial. Joumal of Experimental Psychology: Animal Behavior Processes, 2, 335-345.

Magnussen, S., KURTEnbaCh, W. (1980a). Adapting to two orientations: Disinhibition in a visual aftereffect. Science, 207, 908-909.

Magnussen, S., KuRTenbach, W. (1980b). Linear summation of tilt illusion and tilt aftereffect. Vision Research, 20, 39-42.

MaY, J. G., \& MAPperson, H. H. (1976). Spatial frequency-contingent color aftereffects. Science, 194, 145-147.

McCarter, A., Silver, A. (1977). The McCollough effect: A classical conditioning phenomenon? Vision Research, 17, 317-319.

McCollough, C. (1965). Color adaptation of edge-detectors in the human visual system. Science, 149, 1115-1116.

Mikaelian, H. H. (1976). Plasticity of orientation specific chromatic aftereffects. Vision Research, 16, 459-462.

Mis, F. W., MoORE, J. W. (1973). Effect of preacquisition UCS exposure on classical conditioning of the rabbit's nictating membrane response. Learning \& Motivation, 4, 108-114.

MurCH, G. M. (1976). Classical conditioning of the McCollough effect: Temporal parameters. Vision Research, 16, 615-619.

Phillips, C. G., ZeKI, S., \& BArLow, H. B. (1984). Localization of function in the cerebral cortex. Brain, 107, 327-361.

Rescorla, R. A. (1970). Reduction in the effectiveness of reinforcement after prior excitatory conditioning. Learning \& Motivation, 1 , 372-381.

Rescorla, R. A., \& Waner, A. R. (1972). A theory of Pavlovian conditioning: Variations in the effectiveness of reinforcement and nonreinforcement. In A. H. Black \& W. F. Prokasy (Eds.), Classical conditioning II: Current research and theory (pp. 64-99). New York: Appleton-Century-Crofts.

Riggs, L. A., White, K. D., Eimas, P. D. (1974). Establishment and decay of orientation-contingent aftereffects of color. Perception \& Psychophysics, 16, 535-542.

St. Clair-Smith, R., \& Macieintosh, N. J. (1974). Complete suppression to a compound CS does not block further conditioning to each element. Canadian Journal of Psychology, 28, 92-101.

SChmidt, M. J., PinetTe, P., Finke, R. (1978). Further evidence for conditioning processes in the McCollough effect. Journal of General Psychology, 99, 117-132.

Shute, C. C. D. (1979). The McCollough effect: An indicator of central nerve transmitter activity. Cambridge, England: Cambridge University Press.

Siegel, S., All.an, L. G. (1985). Overshadowing and blocking of the orientation-contingent color aftereffect: Evidence for a conditioning mechanism. Learming \& Motivation, 16, 125-138.

Skоwво, D. (1984). Are McCollough effects conditioned responses? Psychological Bulletin, 96, 215-226.

SkowBo, D. (1986). McCollough effects as conditioned responses? Reply to Allan and Siegal. Psychological Bulletin, 100, 394-397.

STromeYer, C. F., III. (1978). Form-color aftereffects in human vision. In H. Teuber \& R. Held (Eds.), Handbook of sensory physiology (Vol. 8, pp. 97-142). New York: Springer-Verlag.

Timney, B., Gentry, T., Skowbo, D., \& Morant, R. B. (1974). Chro- 
matic grating thresholds and the McCollough effect. Vision Research, 14, 1033-1035.

UTTLEY, A. M. (1979). Information transmission in the nervous system. New York: Academic Press.

WESTBROOK, R. F., HARRISON, W. (1984). Associative blocking of the McCollough effect. Quarterly Joumal of Experimental Psychology, 36A, 309-318.
WhITE, K. D. (1976). Luminance as a parameter in establishment and testing of the McCollough effect. Vision Research, 16, 297-302.

White, K. D., \& RigGs, L. A. (1974). Angle-contingent color aftereffects. Vision Research, 14, 1147-1154.

(Manuscript received March 28, 1988; revision accepted for publication August 9, 1988.) 